\title{
Perception and satisfaction regarding breast feeding among breast feeding mothers: a hospital based study
}

\author{
Vimarshitha Prakash ${ }^{1}$, Sheela S. R. ${ }^{1 *}$, Krithika Raj ${ }^{1}$, Pradeep Tarikere Satyanarayana ${ }^{2}$
}

\begin{abstract}
${ }^{1}$ Department of Obstetrics and Gynecology, Sri Devaraj Urs Medical College, SDUAHER, Kolar, Karnataka, India
${ }^{2}$ Department of Community Medicine, SDUMC, SDUAHER, Kolar, Karnataka, India
\end{abstract}

Received: 15 October 2020

Accepted: 04 December 2020

\author{
*Correspondence: \\ Dr. Sheela S. R., \\ E-mail: dr.pradeep.ts@gmail.com
}

Copyright: (C) the author(s), publisher and licensee Medip Academy. This is an open-access article distributed under the terms of the Creative Commons Attribution Non-Commercial License, which permits unrestricted non-commercial use, distribution, and reproduction in any medium, provided the original work is properly cited.

\begin{abstract}
Background: World Health organization (WHO) states that to ensure child health and survival, Breast feeding can be best tool. It also mentions that nearly 2 out of 3 are not exclusively breast fed and a special note that only $41 \%$ are exclusively breast fed for 6 months. Breastfeeding satisfaction is defined as, "the satisfying feeling obtained during breastfeeding resulting from cooperation between the mother and the infant to fulfill desires or needs".

Methods: This was a hospital based cross sectional study carried at Department of Obstetrics and Gynecology, Sri Devaraj Urs Medical College, SDUAHER, Kolar from December 2019 to August 2020 for a period of 10 months. Sample size was calculated based on previous study.

Results: The present study was a cross sectional study carried out for a period of 9 months at SDUMC tertiary care center. 270 mothers were part of study among which $82(30.3 \%)$ had completed high school, $110(40.7 \%)$ belonged to 21-25 years, 184 (68.07\%) were Hindus, 125 (46.2\%) belonged to Upper middle class of Modified BG Prasad's classification 2019, 199 (73.6\%) had delivered through normal delivery and $142(52.7 \%)$ had more than one child. Out of 270 breast feeding mothers, $214(79.3 \%)$ has satisfactory knowledge, $148(54.8 \%)$ had satisfactory attitude and only $47(17.4 \%)$ had satisfactory practice. Mothers having higher education status, having more than one child, home makers and those delivered by Normal delivery had higher scores were statistically significant.

Conclusions: Perceptions regarding breast feedings were not satisfactory at various segments and breast feeding satisfaction were influenced by education, working status, number of children and family members were significant factors influencing breast feeding satisfaction.
\end{abstract}

Keywords: Breast feeding, Maternal enjoyment, Satisfaction

\section{INTRODUCTION}

World Health organization (WHO) states that to ensure child health and survival, Breast feeding can be best tool. It also mentions that nearly 2 out of 3 are not exclusively breast fed and a special note that only $41 \%$ are exclusively breast fed for 6 months. Breast feeding is an important step which bonds the mother and child and this step starts immediately after birth ideally in the labor ward. According to WHO, Globally three children out of five will not breast feed within one hour of delivery. ${ }^{1}$
Breastfeeding provides a great vehemence between breast feeding mother and breast feeding baby, creating a powerful emotional and psychological bonding which only a breast feeding mother can accomplish. Breast feeding can be more successful when mother realizes her changing behaviour of the child, benefits relished by both breast feeding mother and breast fed child and indirectly promoting positive health related behaviour. With alarming raise in Cesarean sections throughout the world, early initiation of breast feeding has drastically been affected. Studies have shown that incision pain, postural 
limitation and delayed breastfeeding after cesarean section all increase the difficulty of breastfeeding, resulting in the low success rate of breastfeeding among cesarean section women. ${ }^{2}$

Breastfeeding satisfaction is defined as, "the satisfying feeling obtained during breastfeeding resulting from cooperation between the mother and the infant to fulfill desires or needs". ${ }^{3}$ Maternal breast feeding satisfaction is one of the potentially modifiable factors which is consistently linked with positive breast feeding outcomes. Maternal satisfaction can be influenced by various psychological and social barriers, breast feeding policy at hospital, effort mother experiences during feeding and occupational status., ${ }^{4,5}$ Breast milk substitutes and its advocacy being the emerging threat in execution of exclusive breast feeding added with working mother facing difficulties during office hours to breast feed influences the mother to breast feed the child. With this background, the study was started with the objectives to assess maternal breast feeding satisfaction and to assess factors influencing maternal breast feeding satisfaction among mothers who are breast feeding in a tertiary care hospital.

\section{METHODS}

This was a hospital based cross sectional study carried at Department of Obstetrics and Gynecology, Sri Devaraj Urs Medical College, SDUAHER, Kolar from December 2019 to August 2020 for a period of 9 months.

Sample size was calculated based on previous study which had prevalence of Breast feeding satisfaction as $53.4 \%$ and error of $10 \%$ with $95 \%$ confidence interval using n Master Version 2.0, CMC Vellore, Tamil Nadu, India which was 100 and with effect size 2, the estimated final sample size was $200 .^{6}$ Mothers aged 18 years and above who have at least one child and have breast fed were included in the study. Mothers who delivered still birth, Mothers with already diagnosed mental abnormalities were excluded. Data regarding sociodemographic profile was noted with pretested predesigned semi structured questionnaire and maternal breast feeding assessed using Christopher MBFES scale by interview technique. Knowledge attitude and practice was assessed by pretested, predesigned semi structured questionnaire which had 7 questions in knowledge, attitude and practice sections. The correct answer was awarded one point and knowledge attitude and practice was defined satisfactory when there average was more than 4. Christopher MBFES scale is a Likert scale and assesses the three sectors of Breast feeding which are Maternal Enjoyment /Role attainment, Infant satisfaction/growth and Life style /Maternal body image. Prior permission for usage of MBFS was taken. Data were collected on three Out Patient days per week. Simple random sampling method was applied. All the data collected was by interview technique and entered in Microsoft excel sheet. Analysis done using SPSS v 22. The Socio-demographic data will be expressed in frequency and percentages. To find out association between various factors Chi- square test was applied and to compare various groups Independent $\mathrm{T}$ test was applied. $\mathrm{P}$ value is defined statistically significant when less than 0.05 .

\section{RESULTS}

Out of 270 breast feeding mothers, 82 (30.3\%) had completed high school, $61(22.6 \%)$ had completed diploma, $61(22.6 \%)$ had completed graduation. 200 $(70.07 \%)$ were homemakers, $110(40.7 \%)$ belonged to 21 25 years and $107(39.6 \%)$ belonged to $26-30$ years, 184 $(68.07 \%)$ were Hindus, $199(73.6 \%)$ had delivered through normal delivery, $142(52.7 \%)$ had more than one child, $125(46.2 \%)$ belonged to upper middle class of Modified BG Prasad's classification 2019 and 181 $(66.9 \%)$ had family members less than $5.58(43 \%)$ of mothers who were more than 25 years, 81 (39.1\%) who had undergone normal delivery, $63(39.6 \%)$ having more than one child, $59(41.8 \%)$ having education more than high school, $76(38.4 \%)$ who were home makers had satisfactory perceptions regarding breast feeding. 89 $(44.5 \%)$ who were Hindu and $69(44.2 \%)$ who belonged to upper class and upper middle class had satisfactory perceptions regarding breast feeding which was statistically significant.

Table 1: Distribution of study participants according to various socio-demographic factors.

\begin{tabular}{|llll|}
\hline Socio-demographic factors & & Frequency & \multicolumn{1}{c|}{ Percent } \\
\hline \multirow{4}{*}{ Maternal education } & Illiterate & 16 & 5.9 \\
\cline { 2 - 4 } & Primary school & 15 & 5.5 \\
\cline { 2 - 4 } & Middle school & 34 & 12.6 \\
\cline { 2 - 4 } & High school & 82 & 30.3 \\
\cline { 2 - 4 } & Diploma & 61 & 22.6 \\
\cline { 2 - 4 } Occupation & Graduate & 62 & 23.1 \\
\hline \multirow{2}{*}{ Age in years } & Home maker & 200 & 74.07 \\
\cline { 2 - 4 } & Employed & 70 & 6.3 \\
\hline
\end{tabular}

Continued. 


\begin{tabular}{|llll|}
\hline Socio-demographic factors & & Frequency & Percent \\
\hline & $26-30$ & 107 & 39.6 \\
\cline { 2 - 4 } & $31-35$ & 11 & 4.0 \\
\cline { 2 - 4 } & 35 and above & 25 & 9.4 \\
\hline \multirow{3}{*}{ Religion } & Hindu & 184 & 68.07 \\
\cline { 2 - 4 } & Muslim & 56 & 20.73 \\
\cline { 2 - 4 } & Others & 30 & 11.2 \\
\hline \multirow{2}{*}{ Mode of delivery } & Normal Delivery & 199 & 73.6 \\
\cline { 2 - 4 } & LSCS & 71 & 26.4 \\
\hline \multirow{2}{*}{ Number of child } & Less than 1 child & 128 & 47.3 \\
\hline \multirow{5}{*}{ Modified BG Prasad Classi-fication 2019} & More than 1 child & 142 & 52.7 \\
\cline { 2 - 4 } & Upper class & 26 & 9.6 \\
\cline { 2 - 4 } & Upper middle & 130 & 48.1 \\
\cline { 2 - 4 } & Middle & 69 & 25.6 \\
\cline { 2 - 4 } & Lower middle & 37 & 13.7 \\
\hline \multirow{2}{*}{ Total number of family members } & Lower & 8 & 3.0 \\
\cline { 2 - 4 } & Less than 5 & 181 & 66.9 \\
\cline { 2 - 4 } & More than 5 & 89 & 33.1 \\
\hline
\end{tabular}

Table 2: Distribution of study participants according to the knowledge, attitude and practice regarding breast feeding.

\begin{tabular}{|llll|}
\hline \multirow{2}{*}{ Kerceptions } & & Frequency & Percent \\
\hline \multirow{2}{*}{ Attitude } & Not satisfactory & 56 & 20.7 \\
\cline { 2 - 4 } & Satisfactory & 214 & 79.3 \\
\hline \multirow{2}{*}{ Practice } & Not satisfactory & 122 & 45.2 \\
\cline { 2 - 4 } & Satisfactory & 148 & 54.8 \\
\cline { 2 - 4 } & Not satisfactory & 223 & 82.6 \\
\cline { 2 - 4 } & Satisfactory & 47 & 17.4 \\
\hline
\end{tabular}

Table 3: Association between breast feeding perceptions and various factors.

\begin{tabular}{|c|c|c|c|c|}
\hline Various factors & & Not satisfactory & Satisfactory & $P$ value \\
\hline \multirow{2}{*}{ Age in years } & Less than 25 & $90(66.7 \%)$ & $45(33.3 \%)$ & \multirow{2}{*}{0.135} \\
\hline & More than 25 & $77(57 \%)$ & $58(43 \%)$ & \\
\hline \multirow{2}{*}{ Religion } & Hindu & $111(55.5 \%)$ & $89(44.5 \%)$ & \multirow{2}{*}{0.001} \\
\hline & Others & $56(80 \%)$ & $14(20 \%)$ & \\
\hline \multirow{2}{*}{ Mode of delivery } & Normal delivery & $126(60.9 \%)$ & $81(39.1 \%)$ & \multirow{2}{*}{0.32} \\
\hline & Lower segment cesarean section & $41(65.1 \%)$ & $22(34.9 \%)$ & \\
\hline \multirow{2}{*}{ Number of children } & One child & $71(64 \%)$ & $40(36 \%)$ & \multirow{2}{*}{0.5} \\
\hline & More than one child & $96(60.4 \%)$ & $63(39.6 \%)$ & \\
\hline \multirow{2}{*}{ Education } & Up to high school & $85(65.9 \%)$ & $44(34.1 \%)$ & \multirow{2}{*}{0.6} \\
\hline & More than high school & $82(58.2 \%)$ & $59(41.8 \%)$ & \\
\hline \multirow{2}{*}{ Occupation } & Home maker & $122(61.6 \%)$ & $76(38.4 \%)$ & \multirow{2}{*}{0.8} \\
\hline & Working mother & $45(62.5 \%)$ & $27(37.5 \%)$ & \\
\hline \multirow{2}{*}{$\begin{array}{l}\text { Modified BG Prasad } \\
\text { Classification } 2019\end{array}$} & $\begin{array}{l}\text { Upper class and upper middle } \\
\text { class }\end{array}$ & $87(55.8 \%)$ & $69(44.2 \%)$ & \multirow{2}{*}{0.001} \\
\hline & $\begin{array}{l}\text { Middle, lower middle and lower } \\
\text { class }\end{array}$ & $80(70.2 \%)$ & $34(29.8 \%)$ & \\
\hline
\end{tabular}

Table 4: Comparison between of study participants according to the maternal breast-feeding satisfaction scores.

\begin{tabular}{|llll|}
\hline Variables & Maternal enjoyment & $\begin{array}{l}\text { Infant } \\
\text { satisfaction }\end{array}$ & $\begin{array}{l}\text { Lifestyle and maternal } \\
\text { body image }\end{array}$ \\
\hline Education up to high school & $54.5 \pm 5.7$ & $29.0 \pm 4.0$ & $31.4 \pm 5.3$ \\
\hline Education more than high school & $59.1 \pm 5.3$ & $31.7 \pm 3.5$ & $31.6 \pm 4.3$ \\
\hline
\end{tabular}




\begin{tabular}{|llll|}
\hline Variables & Maternal enjoyment & $\begin{array}{l}\text { Infant } \\
\text { satisfaction }\end{array}$ & $\begin{array}{l}\text { Lifestyle and maternal } \\
\text { body image }\end{array}$ \\
\hline p value & 0.04 & 0.03 & 0.7 \\
\hline Family members less than 5 & $59.5 \pm 5.6$ & $31.9 \pm 3.7$ & $31.6 \pm 5.0$ \\
\hline Family members more than 5 & $54.7 \pm 5.3$ & $27.7 \pm 3.9$ & $28.7 \pm 4.9$ \\
\hline p value & 0.02 & 0.03 & 0.04 \\
\hline Less than one child & $54.2 \pm 6.0$ & $29.6 \pm 3.7$ & $28.1 \pm 5.1$ \\
\hline More than one child & $59.4 \pm 5.1$ & $32.1 \pm 3.8$ & $31.8 \pm 4.7$ \\
\hline p value & 0.007 & 0.04 & 0.02 \\
\hline Age less than 25 years & $59.1 \pm 5.6$ & $31.8 \pm 3.7$ & $31.4 \pm 5.3$ \\
\hline Age more than 25 years & $59.7 \pm 5.4$ & $31.9 \pm 3.8$ & $31.7 \pm 4.4$ \\
\hline p value & 0.5 & 0.8 & 0.6 \\
\hline Home maker & $59.6 \pm 5.7$ & $32.1 \pm 3.8$ & $32.02 \pm 4.9$ \\
\hline Working mother & $58.1 \pm 4.4$ & $30.8 \pm 3.3$ & $29.7 \pm 4.4$ \\
\hline p value & 0.08 & 0.04 & 0.03 \\
\hline Normal delivery & $59.6 \pm 5.7$ & $32.0 \pm 3.9$ & $31.7 \pm 5.0$ \\
\hline Lower segment cesarean section & $58.2 \pm 4.6$ & $31.2 \pm 3.3$ & $30.8 \pm 4.1$ \\
\hline p value & 0.08 & 0.1 & 0.1 \\
\hline
\end{tabular}

Table 5: Correlation between perceptions and maternal breast feeding scores.

\begin{tabular}{|c|c|c|c|c|}
\hline \multirow{3}{*}{$\begin{array}{l}\text { Perceptions } \\
\text { regarding breast } \\
\text { feeding }\end{array}$} & & $\begin{array}{l}\text { Maternal } \\
\text { enjoyment }\end{array}$ & Infant satisfaction & $\begin{array}{l}\text { Lifestyle and maternal } \\
\text { body image }\end{array}$ \\
\hline & Pearson correlation & 0.220 & 0.142 & 0.2 \\
\hline & $P$ value & 0.001 & 0.02 & 0.002 \\
\hline
\end{tabular}

Out of 270 breast feeding mothers, 82 (30.3\%) had completed high school, $61(22.6 \%)$ had completed diploma, $61(22.6 \%)$ had completed graduation. 200 $(70.07 \%)$ were homemakers, $110(40.7 \%)$ belonged to $21-$ 25 years and $107(39.6 \%)$ belonged to $26-30$ years, 184 $(68.07 \%)$ were Hindus, $199(73.6 \%)$ had delivered through normal delivery, $142(52.7 \%)$ had more than one child, 125 (46.2\%) belonged to upper middle class of Modified BG Prasad's classification 2019 and 181 $(66.9 \%)$ had family members less than 5. 58 (43\%) of mothers who were more than 25 years, 81 (39.1\%) who had undergone normal delivery, 63 (39.6\%) having more than one child, $59(41.8 \%)$ having education more than high school, 76 (38.4\%) who were home makers had satisfactory perceptions regarding breast feeding. 89 (44.5\%) who were Hindu and 69 (44.2\%) who belonged to upper class and upper middle class had satisfactory perceptions regarding breast feeding which was statistically significant.

Out of 270 breast feeding mothers, 214 (79.3\%) has satisfactory knowledge, $148(54.8 \%)$ had satisfactory attitude and only $47(17.4 \%)$ had satisfactory practice. Mothers having education higher than high school, mothers with family members less than 5 in number, mothers having more than one child and homemakers had higher scores with respect to infant satisfaction where the difference was statistically significant. Mothers with family members less than 5, mothers who were homemakers, mothers with more than one child had better scores with respect to lifestyle and maternal body image where the difference was statistically significant. Mothers who had undergone normal delivery had better scores compared with those undergoing Cesarean section however the difference was not statistically significant.

There was positive correlation between perceptions regarding breast feeding and maternal breast feeding satisfaction scores which was statistically significant.

\section{DISCUSSION}

The present study was a cross sectional study carried out for a period of 6 months at SDUMC tertiary care center. 270 mothers were part of study among which $82(30.3 \%)$ had completed high school, $110(40.7 \%)$ belonged to 21 25 years, 184 (68.07\%) were Hindus, 125 (46.2\%) belonged to upper middle class of Modified BG Prasad's classification 2019, $199(73.6 \%)$ had delivered through normal delivery and142 $(52.7 \%)$ had more than one child. Out of 270 breast feeding mothers, 214 (79.3\%) has satisfactory knowledge, 148 (54.8\%) had satisfactory Attitude and only $47(17.4 \%)$ had satisfactory practice. Mothers having higher education status, having more than one child, home makers and those delivered by normal delivery had higher scores were statistically significant.

Study done by Awaliyah et al showed normal delivery, lower income and older age had better breastfeeding scores. ${ }^{6}$ Study done by Dodt et al using breast feeding 
self-efficacy scale showed similar findings where mothers with better education and previous breast feeding practice had higher scores which are similar to our study.

The present study showed higher scores in Breast feeding satisfaction among mothers who were home makers. Study done by Sattari et al showed working mothers had maternal infant-feeding intentions and work-related factors both play important roles in physician mothers' infant-feeding behavior. Longer maternity leave, regulations to support breastfeeding among working mothers, and workplace support might significantly improve mothers' Breast Feeding Practices. ${ }^{8}$ Education level, previously having breast feeding experience, having more than two public health nurse visits, and having a positive infant feeding attitude were independently and statistically significantly associated with breast feeding. ${ }^{9}$ Interventions promoting behavior change with regards to breastfeeding should focus on dispelling the beliefs and practices. ${ }^{10}$ The present study showed that $79.3 \%$ had satisfactory knowledge, $54.8 \%$ had satisfactory attitude and only $44.5 \%$ had satisfactory practice with religion and socio-economic status being statistically significant factors influencing knowledge attitude and practice. Study done by Malik et al regarding timely start of breast feeding and knowledge regarding breast feeding among post natal mothers in a baby friendly hospital showed that increasing age of mother, education status, better socioeconomic status, joint family affected knowledge favorably, whereas age of mother below 20, first childbirth adversely affected the score which were similar to present study. ${ }^{11}$

The present study showed even though the knowledge of Breast feeding was high among mothers but practice was poor showing a gap needs to be filled between knowledge and practice by changing the attitude and the right place to do this would be in the postnatal wards. Study done by Bhatt Shwetal et al regarding knowledge, attitude and practice of postnatal mothers for early initiation of breast feeding in the obstetric wards showed that lack of adequate information, maternal education level, socioeconomic factors influences the early breast feeding practices which can be overcome by proper support, care and counseling provided by health care staff. ${ }^{12}$

The present study used validated questionnaire to assess maternal breast feeding satisfaction and data were collected by interview technique.

\section{Limitations}

Inherited bias associated with cross sectional studies. Recommendation of the study are Health education to be initiated as early as possible especially during antenatal visits and baby friendly hospital policies needs to be implemented with more vigilance.

\section{CONCLUSION}

Perceptions regarding breast feedings were not satisfactory at various segments and breast feeding satisfaction were influenced by education, working status, number of children and family members were significant factors influencing Breast feeding Satisfaction.

Funding: No funding sources

Conflict of interest: None declared

Ethical approval: The study was approved by the Institutional Ethics Committee

\section{REFERENCES}

1. Breastfeeding. Available at https:// www. who.int/westernpacific/health-topics/breastfeeding. Accessed on 20 August 2020.

2. Hu L, Ding T, Hu J, Luo B. Promoting breastfeeding in Chinese women undergoing cesarean section based on the health belief model: a randomized controlled trial. Medicine. 2020;10:99(28).

3. Hobbs AJ, Mannion CA, McDonald SW, Brockway M, Tough SC. The impact of caesarean section on breastfeeding initiation, duration and difficulties in the first four months postpartum. BMC Pregnancy Childbirth. 2016;26:90.

4. Ahmed AA, Hassan AK, Mohamed SH, Hamad MA. Self-efficacy of postpartum mothers toward breastfeeding and the affecting factors. Am J Nursing. 2020;8(3):352-60.

5. Piro SS, Ahmed HM. Impacts of antenatal nursing interventions on mothers' breastfeeding self-efficacy: an experimental study. BMC Pregnancy Childbirth. 2020;20(1):19.

6. Awaliyah SN, Rachmawati IN, Rahmah H. Breastfeeding self-efficacy as a dominant factor affecting maternal breastfeeding satisfaction. BMC Nursing. 2019;18(1):30.

7. Dodt RC, Ximenes LB, Almeida PC, Oria MB, Oliveira CL. Psychometric and maternal sociodemographic assessment of the breastfeeding self-efficacy scale-short form in a brazilian sample. J Nursing Edu Practice. 2012;2(3):66.

8. Zhu J, Chan WC, Zhou X, Ye B, He HG. Predictors of breast feeding self-efficacy among Chinese mothers: a cross-sectional questionnaire survey. Midwifery. 2014;30(6):705-11.

9. Sattari M, Levine DM, Mramba LK, Pina M, Raukas R, Rouw E, et al. Physician mothers and breastfeeding: a cross-sectional survey. Breastfeeding Med. 2020;15(5):312-20.

10. Leahy WP, Mulcahy H, Phelan A, Corcoran P. Factors influencing initiation and duration of breast feeding in Ireland. Midwifery. 2014;30(3):345-52.

11. Mallik S, Dasgupta U, Naskar S, Sengupta D, Choudhury K, Bhattacharya SK. Knowledge of breast feeding and timely initiation of it amongst post natal mothers: an experience from a baby 
friendly teaching hospital of a metropolitan city. IOSR J Dental Med Sci. 2013;4(1):25-30.

12. Shwetal B, Pooja P, Neha K, Amit D, Rahul P. Knowledge, attitude and practice of postnatal mothers for early initiation of breast feeding in the obstetric wards of a tertiary care hospital of Vadodara city. Hindu. 2012;134:81-5.
Cite this article as: Prakash V, Sheela SR, Raj K, Satyanarayana PT. Perception and satisfaction regarding breast feeding among breast feeding mothers: a hospital based study. Int J Reprod Contracept Obstet Gynecol 2021;10:233-8. 